PSICOLOGIA, SAÚDE \& DOENÇAS, 2020, 21(1), 3-7

ISSN - 2182-8407

Sociedade Portuguesa de Psicologia da Saúde - SPPS - www.sp-ps.pt

DOI: http://dx.doi.org/10.15309/20psd210102

\title{
ADAPTING THE GLOBAL MEANING VIOLATION SCALE FOR USE WITH ARABIC-SPEAKING REFUGEES
}

\author{
Lisa Matos ${ }^{1}$, Monica Indart ${ }^{2}$, Crystal Park $^{3}, \&$ Isabel Leal $^{1}$ \\ ${ }^{1}$ WJCR - William James Center for Research, ISPA - Instituto Universitário, Lisbon, Portugal, lmatos@ispa.pt \\ ${ }^{2}$ Graduate School of Applied and Professional Psychology, Rutgers University, New Brunswick, New Jersey, USA \\ ${ }^{3}$ Department of Psychological Sciences, University of Connecticut, Storrs, Connecticut, USA
}

\begin{abstract}
Refugees are survivors of extreme, cumulative potentially-traumatic events (PTEs), which can violate their goals, beliefs and sense of purpose (i.e. global meaning) and cause significant psychological distress. Despite being disproportionately affected by PTEs, there are few psychological instruments available in refugees' native languages, and which consider their cultural and traumatic diversity. Our aim is to describe the process of cross-cultural adaption of the Global Meaning Violation Scale (GMVS) for use with Arabic-speaking refugees in resettlement. Methods: Following the ITC Guidelines for Translating and Adapting Tests, we engaged the assistance of psychometry, language, cultural and content experts to translate and adapt the GMVS to Arabic. Results: Experts based in Portugal, Jordan, US and Germany participated in the translation and adaptation process. The scale was considered straightforward and overall cohesive and, by addressing feelings rather than mental health issues, culturallyappropriate. Potential problems related to the complexity of the construct, cultural appropriateness of the "Intimacy (emotional closeness)" item, and use of a Likert Scale. Discussion: The overall process of translating and adapting the GMVS to Arabic was lengthy and resource-intensive. Researchers should carefully consider availability of resources when planning research with culturally diverse populations.
\end{abstract}

Keywords: refugee trauma, meaning-making, cross-cultural adaptation, scale validation, psychological instruments.

الملخص: يعتبر اللاجئون ناجين من أحداث قاسية، نر اكمية، وذات قدرة على ترك صدمة (PTEs)، و التي بدور ها

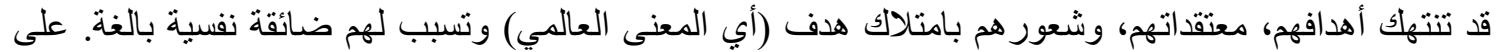

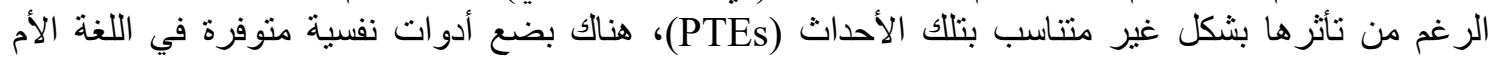

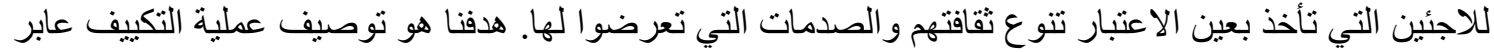

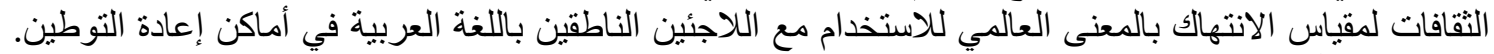

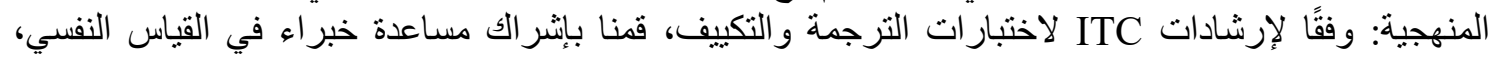

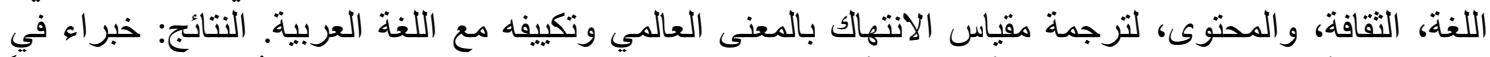

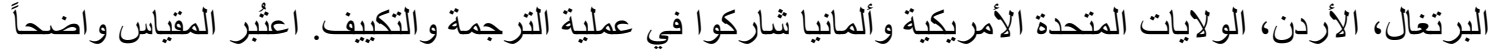

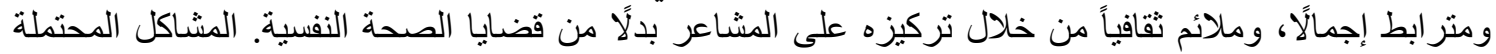

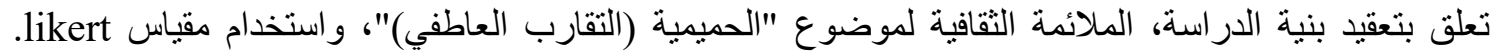
المناقثة: كانت العملية العامة لترجمة وتكييف مقياس الانتهاك بالمعنى العالمي للغة العربية عملية طويلة ومنطلبة 


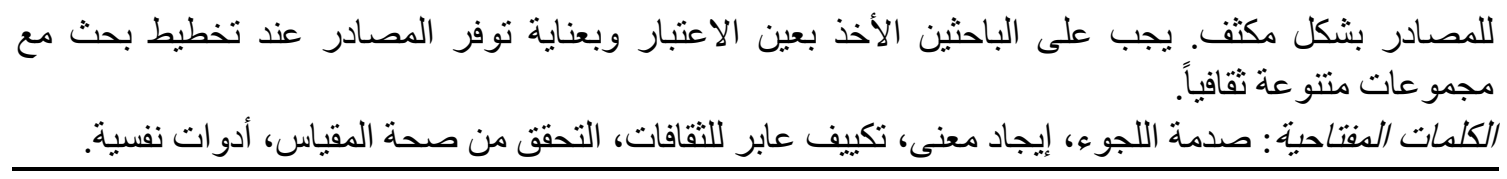

\section{ADAPTAÇÃO DA GLOBAL MEANING VIOLATION SCALE PARA REFUGIADOS DE LÍNGUA ÁRABE}

RESUMO: Os refugiados são sobreviventes de múltiplos acontecimentos potencialmente traumáticos (PTEs), de caráter extremo, que podem desestruturar os seus objetivos, crenças e senso de propósito (i.e., sentido global) e causar distress psicológico significativo. Apesar de serem desproporcionalmente afetados por PTEs, há poucos instrumentos psicológicos que integram a diversidade cultural e traumática das populações refugiadas e que estão disponíveis nas suas línguas maternas. O nosso objetivo é descrever o processo de tradução e adaptação cultural da Global Meaning Violation Scale (GMVS) para refugiados falantes de árabe. Métodos: Seguindo as diretrizes da ITC para tradução e adaptação de testes, procedemos à adaptação transcultural da GMVS para árabe, através de um comité de especialistas em psicometria, conteúdo, língua e culturas árabes para traduzir e adaptar a GMVS. Resultados: Reunimos um conjunto de especialistas sediados em Portugal, Jordânia, EUA e Alemanha para traduzir e adaptar a GMVS. A escala foi considerada simples, globalmente coesa e, ao focar-se em sentimentos e não em questões de saúde mental, foi considerada culturalmente apropriada. Foram identificados potenciais problemas relativos à complexidade do construto, adequação cultural do item "Intimidade (proximidade emocional)" e utilização de escala de Likert. Discussão: O processo de tradução e adaptação da GMVS para árabe foi moroso e muito exigente em termos de recursos. É fundamental que os investigadores tenham especial atenção à disponibilidade e acesso a recursos, no trabalho com populações culturalmente diversas. Palavras-chave: Trauma, Experiência de refúgio, Atribuição de sentido, Adaptação transcultural, Validação de escala; Instrumentos psicológicos

Recebido em 15 de Novembro de 2019/ Aceite em 29 de Janeiro de 2020

The refugee experience is characterized by forced migration journeys, during which survivors are exposed to extreme, cumulative Potentially-Traumatic Events (PTEs), including war and torture (Steel et al., 2009). These PTEs can be frightening, painful and senseless, and may challenge refugees' deeply-held beliefs about themselves, the world and their place in the world, their life goals and their sense of purpose (i.e. their global meaning, Park, 2010). The perceived discrepancy between the meanings survivors of the refugee experience ascribe to their experiences and their global meaning systems can cause intense distress, which is evidenced by the prevalence of high rates of psychopathology in refugee populations, even in postdisplacement (Heeren et al., 2014).

In the wake of the 2015 surge of refugees in the Southern shores of Europe, countries across Europe, including Portugal, saw a significant increase in arrivals of Syrian, Iraqi and Eritrean nationals and other refugee communities (EC, 2015). Besides fleeing war and generalized violence in their countries of origin, these refugees endured long periods of instability in countries of first asylum, and further risked their lives crossing the Mediterranean (Satinsky, Fuhr, Woodward, \& Sondorp, 2019). Thus, there was an urgency to offer evidence-based, trauma-informed, culturally- 


\section{GMVS ADAPTATION FOR ARABIC-SPEAKING REFUGEES}

competent interventions that promote psychological health as a pre-condition to successful, longterm integration of the refugees.

Central to the process of recovering from trauma is the ability to make meaning of past experiences through cognitive restructuring efforts; these can either change individuals' perceptions of the event to make it congruent with their existing system of beliefs (Park, 2016), or change their set of assumptions about the world to account for the traumatic event. Restoring congruence between experience and meaning systems thereby leads to positive psychological adjustment (Davis, Wohl, \& Verberg, 2007).

To better understand trauma survivors' meaning-making processes, Park and colleagues (2016) developed the Global Meaning Violation Scale (GMVS) to assess violations of beliefs and goals. The 13-item scale is succinct, comprising a belief (5 items) and a goal (6 items) subscale. The GMVS was tested in a subset of the US population (college students) and it was considered psychometrically-valid and reliable, indicating promising results to further advance research on meaning-making.

Considering meaning-making a condition to achieve psychological adjustment and the scarcity of psychological instruments available in refugees' native languages, we translated and culturally adapted the GMVS for use with Arabic-speaking refugees in resettlement.

\section{METHOD}

The International Test Commission (ITC, 2018) establishes 18 guidelines for cross-cultural adaptation of psychological instruments organized in six phases: pre-condition, test development, confirmation, administration, scale scores and interpretation, and documentation. In this article, we describe the first 2 phases; the latter 4 will be addressed in a scale validation article at a later time.

Although the formal Arabic language is the official language in all Arab countries, the GMVS was primarily intended for use with Syrian and Iraqi nationals recently arrived in Portugal; thus, we prioritized the assembly of a committee of experts who could account for specific differences in spoken language, communication methods and idioms of distress (Amro et al., 2019) of these communities. Assembling such a committee was particularly hard to achieve in a country like Portugal, which has very small Syrian and Iraqi communities. Besides providing a small pool of potential language and cultural experts, most refugees are recently-arrived and may still be in significant distress as they try to settle and navigate new systems. They may be suspicious of researchers and may not have sufficient English language knowledge to assist with research tasks. It is worth mentioning that having the research materials available in English rather than Portuguese represented a huge benefit, as it would have been exponentially harder to identify expertise with sufficient Portuguese language fluency.

The expert committee was composed of: two Portuguese-based Syrian translators, one with formal Arabic-English-Arabic translation and interpretation training, currently working as a cultural mediator, and one graduate student with a degree in English literature; one Jordanian psychologist and researcher working on meaning-making issues with refugees in Amman; one Syrian-American mental health researcher working with Syrian communities in Germany and Lebanon; one USbased refugee trauma expert; the first author herself, who has extensive field experience working with survivors of torture and refugee trauma; and one PhD-level psychometrist. 


\section{RESULTS}

Following the ITC guidelines, we began by (1) obtaining permission from the GMVS' authors to translate, adapt and test it in Arabic-speaking populations with refugee-like experiences. Considering the differences between both cultures and the anticipated severity and cumulative nature of PTEs, the possibility of the GMVS being a useful tool to a particularly traumatized population was regarded with great excitement by the authors.

The second step (2) pertained to assessing and ensuring that the construct was culturallyappropriate and similarly understood in both languages and cultural groups. As such, we recruited language, cultural and content experts based in Portugal, Jordan, Germany and the US, to whom the construct "global meaning" was separately explained. Each expert was subsequently shown the scale. Despite the complexity of the construct and the level of abstraction required by questions in the scale, there were no concerns about culturally-informed disparities between the construct in its original and in the target language and culture.

The third step (3) entailed minimizing the cultural and linguistic differences, namely participants' potential motivations, their understanding of instructions, and experience with psychological tests or familiarity with rating scales. As a whole, the experts raised four main concerns. The first concern a) pertained to the cultural bias associated with using Likert-type scales (Lee et al., 2002), namely the potential for extreme response bias in Arab populations (Baron-Epel, Kaplan, Weinstein, \& Green, 2010), as something to be mindful of when analyzing the data. Secondly b) one content expert raised the possibility of including descriptors for all 5 Likert points, rather than just the points of anchorage ( 1 - not at all and 5 - very much), as the original format may not be sufficiently clear for the target population. Hence, a decision was made to test the scale in Focus Group sessions and reserve time for open-ended questions to monitor participants' reactions. The third concern c) pertained to expected insufficient literacy and lower formal education in arriving refugee communities as well as possible lower level of cognitive ability than the complexity required by the construct and the scale format (Baron-Epel et al., 2010). It was thus determined appropriate for the scale to be administered by a clinician or researcher trained to clarify concepts, items and functioning of the scale, rather than it being exclusively self-administered. The final concern d) included attempting to minimize the impact of other motivations for participation. This was achieved through clarification, both in information sessions for prospective participants and in the study instructions at the beginning of the interviews, that participation in the study and the content of participants' answers would not impact their legal status, prospects for family reunification, access to services or any other aspects of their lives in resettlement..

After meeting the pre-conditions in phase 1, we initiated the test development phase. Step four (4) requires ensuring that the translation and adaptation consider linguistic, psychological and cultural differences through experts with relevant expertise. Prior to addressing culture or languagespecific issues (step five), we first attempted to address the diversity and severity of traumas that characterize the refugee experience. As such, with permission from the authors and in consultation with the refugee trauma experts, in the GMVS introductory question, we changed the reference to a single stressor from - When you think how you felt before and after your most stressful experienceto - When you think how you felt before and after the events that led you leave your country. This was done not only to account for the cumulative nature of trauma, but also to avoid the potential for undue distress by asking participants to "choose" the most stressful event; further, the reference to country was preferred over the more specific country of origin or home country as refugees often 


\section{GMVS ADAPTATION FOR ARABIC-SPEAKING REFUGEES}

live in protracted situations (UNHRC, 2018), and may have different points of reference for their forced displacement and traumatic experiences.

The fifth (5) guideline requires appropriate translation designs and procedures to maximize suitability of test adaptation. We combined two translation procedures of forward/backward translation, and double translation and reconciliation with a third independent translator. This method was selected to not only account for the research team's lack of command of the target language, but also to minimize forward/backward translation bias (Gudmudsson, 2009), which could hinder functional equivalence. One Syrian translator and the Jordanian psychologistresearcher, both Arabic-natives, translated the scale to Arabic. All items were considered easy to translate and the scale clear and understandable. A third translator independently reviewed both Arabic versions, finding very few discrepancies; these discrepancies mostly pertained to the translation of the construct "global meaning" and minor lay terminology in the items. We reconciled both versions by opting for the Jordanian content expert's suggested translation of the "global meaning", as al-maa'na for meaning, similar to "sense of meaning" used in the Arabic language literature, and mafhoum for global, which elicits general ideas or collection of characteristics about meaning. The discrepancies in lay terminology were reconciled per the Syrian experts' suggestions, since the scale was meant to be tested in Syrian and Iraqi populations, rather than Jordanian. Of note, the independent translator raised concerns about the appropriateness of item 13 "Intimacy (emotional closeness)", which she immediately associated with issues of sexuality that may make participants uncomfortable. We subsequently sent the translated scale to the Berlin-based SyrianAmerican expert for review, confirmation of functional equivalence, and back translation. This subject-matter expert is a native speaker of both languages, and has extensive experience administrating mental health questionnaires to Arab communities. Her findings were as follows: the scale was overall cohesive, contained no absurd items, the questions were straightforward, and the wording was culturally-sensitive by addressing feelings rather than matters of mental health, which she felt could be problematic. She found the scale to be appropriate for use with the target population.

After completing all these steps, the Arabic version of the GMVS was deemed ready to be pilottested in Focus Group interviews. Data collected from initial testing will then be incorporated for subsequent confirmation in individual interviews with Arabic-speaking refugees.

\section{DISCUSSION}

The overall process of translating and adapting the GMVS for testing in Focus Group interviews with Arabic-speaking refugees was extremely lengthy and at times frustrating. We initiated the process in November 2017 (step 1). After obtaining permission from the authors, we promptly began trying to identify and assemble a committee of experts, and to locate funding sources to pay for translation and interpretation costs. Faced with a lack of in-country language, cultural and content expertise, we made use of our international networks to help locate and connect with colleagues around the world working on similar issues. Following introductions, we cultivated new relationships, adjusted agendas to meet and discuss, and developed new collaborative partnerships. Despite it being unparalleled in how it enriches our work and networks, the process of assembling the expert committee took four months. In March 2018, we were finally ready to initiate step 2. After completing the ITC guidelines as described above, the GMVS, as part of a larger study protocol, was sent to ISPA's Ethics Committee for approval in June 2018. The protocol was 
approved in September 2018 and the GMVS was ready to be piloted in October 2018, 10 months after initiating the process of cross-cultural adaptation.

It is possible that at times we were overly cautious in some of the steps we took to ensure adequate translation, thus unnecessarily extending our timeline. An example of this is having opted for combining two translation methods, where back translation may not have been necessary. However, we determined that the limitations in target language fluency within the research team warranted that additional step (Epstein, Santo, \& Gillemin, 2015), and that the risks of inadequate translation and adaptation of an instrument (Fasfous, Al-Joudi, Puente, \& Perez-Garcia, 2017) that is meant to be used with and to help such deeply traumatized populations was not worth skipping that step.

The main contributions of this study are two-fold: on the one hand, by detailing the methodological steps and rigor we took in adapting the GMVS, we address concerns in the literature about the lack of detailed reporting of the cross-cultural adaptation process and the significant number of poorly adapted tests being used with Arab populations (Uysal-Bozkir, Parlevliet, \& de Rooji, 2013). On the other hand, it is crucial that researchers working with hard-toreach populations that are culturally and linguistically different carefully consider the availability of resources when planning their study designs. Work plans should be sufficiently flexible to accommodate time, funding and other resource demands. Because researchers and experts cannot anticipate all problems encountered by participants, it is essential to conduct small try-outs with the target population, namely through focus groups, prior to test administration. Without appropriate cross-cultural adaptation and subsequent validation of a scale's psychometric properties, the validity of research results may lead to false conclusions.

\section{REFERENCES}

Amro, I., Ghuloum, S., Mahfoud, Z., Opler, M., Khan, A., Hammoudeh, S., ... Al Amin, H. (2019). Cross-cultural adaptation of the Arabic Positive and Negative Syndrome Scale in schizophrenia: Qualitative analysis of a focus group. Transcultural psychiatry, 56(5), 973-991. doi: $10.1177 / 1363461519850345$

Baron-Epel, O., Kaplan, G., Weinstein, R. \& Green, M. (2010). Extreme and acquiescence bias in a bi-ethnic population. European Journal of Public Health, 20, 543-8. doi: 10.1093/eurpub/ckq052

Davis, C., Wohl, M., \& Verberg, N. (2007). Profiles of posttraumatic growth following an unjust loss. Death Studies, 31(8), 693-712. doi: 10.1080/07481180701490578

Epstein, J., Santo, R., \& Guillemin, F. (2015). A review of guidelines for cross-cultural adaptation of questionnaires could not bring out a consensus. Journal of Clinical Epidemiology, 68, 435441. doi: 10.1016/j.jclinepi.2014.11.021

European Commission (2015). Refugee crisis: European Commission takes decisive action Questions and answers. Memo, 15-5597. European Commission website: https://ec.europa.eu/commission/presscorner/detail/en/MEMO_15_5597

Fasfous, A., Al-Joudi, H., Puente, A. \& Perez-Garcia, M. (2017). Neuropsychological measures in the Arab world: A systematic review. Neuropsychology Review, 27, 1-16. doi: 10.1007/s11065017-9347-3

Gudmundsson, E. (2009). Guidelines for translating and adapting psychological instruments. Nordic Psychology, 61(2), 29-45. doi: 10.1027/1901-2276.61.2.29 


\section{GMVS ADAPTATION FOR ARABIC-SPEAKING REFUGEES}

Heeren, M., Wittman, L., Ehlert, U., Schnyder, U., Maier, T., \& Muller, J. (2014). Psychopathology and resident status - Comparing asylum seekers, refugees, illegal migrants, labor migrants, and residents. Comprehensive Psychiatry, 55, 818-825. doi: 10.1016/j.comppsych.2014.02.003

International Test Commission (2018). The ITC Guidelines for Translating and Adapting Tests (Second Edition). International Journal of Testing, 18(2), 101-134. doi: 10.1080/15305058.2017.1398166

Lee, J., Jones, P., Mineyama, Y. \& Zhang, E. (2002). Cultural differences in responses to a Likert scale. Research in Nursing \& Health, 25, 295-306. doi: 10.1002/nur.10041

Park, C. (2010). Making sense of the meaning literature: An integrative review of meaning making and its effects on adjustment to stressful life events. Psychological Bulletin, 136(2), 257-301. doi: $10.1037 / \mathrm{a} 0018301$

Park, C. (2016). Distinctions to promote an integrated perspective on meaning: Global meaning and meaning-making processes. Journal of Constructivist Psychology, 00(00), 1-6. doi: 10.1080/10720537.2015.1119082

Park, C.L., Riley, K.E., George, L.S., Gutierrez, I.A., Hale, A.E., Cho, D., .., Braun T.D. (2016). Assessing disruptions in meaning: Development of the Global Meaning Violation Scale. Cognitive Therapy and Research, 40, 831-846. doi: 10.1007/s10608-016-9794-9

Satinsky, E., Fuhr, D., Woodward, A., Sondorp, E., \& Roberts, B. (2019). Mental health care utilisation and access among refugees and asylum seekers in Europe: A systematic review. Health Policy, 123, 851-863. doi: 10.1016/j.healthpol.2019.02.007

Steel, Z., Chey, T., Silove, D., Marnane, C., Bryant, R., \& van Ommeren, M. (2009). Association of torture and other potentially traumatic events with mental health outcomes among populations exposed to mass conflict and displacement - A systematic review and meta-analysis. JAMA, 302(5), 537-49. doi: 10.1001/jama.2009.1132

United Nations High Commissioner for Refugees (2018). Global trends: Forced displacement in 2018. UNHCR website: https://www.unhcr.org/globaltrends2018/

Uysal-Bozkir, O., Parlevliet, J. \& de Rooij, S. (2013). Insufficient cross-cultural adaptations and psychometric properties for many translated health assessment scales: A systematic review. Journal of Clinical Epidemiology, 66(6), 608-618. doi: 10.1016/j.jclinepi.2012.12.004 